\title{
A institucionalização de sistemas internos de garantia de qualidade, como pilar para o desenvolvimento de processos de autorregulação de IES
}

Juliana da Silva Dias ${ }^{1}$

Cassius Gomes de Oliveira ${ }^{2}$

\section{Resumo}

Este estudo visa analisar os processos regulatórios e avaliativos de instituições portuguesas, por meio dos Sistemas Internos de Garantia da Qualidade, para estabelecer proposições junto ao modelo brasileiro e favorecer os processos de autorregulação. Caracteriza-se tal pesquisa como exploratória, pois se preocupou em identificar fatores determinantes, que contribuíram para a ocorrência dos fenômenos. Na concepção metodológica, configurase pela escolha do método qualitativo, baseada no aprofundamento da compreensão do que se estuda e da análise dos resultados. Como resposta, o estudo revelou que um processo favorecerá a qualidade na medida em que tenha mecanismos de autorregulação robustos, bem desenvolvidos, de forma contínua, com credibilidade junto à comunidade acadêmica.

Palavras-chave: Autorregulação; Qualidade; Educação Superior.

The institutionalization of internal quality assurance systems, as a pillar for the development of self-regulatory processes in higher education institutions

\section{Abstract}

This study aims to analyze the regulatory and evaluative processes of Portuguese institutions, through the Internal Quality Assurance Systems, to establish propositions along the Brazilian model and favor the self-regulatory processes. Such research is characterized as exploratory, as it was concerned with identifying determining factors that contributed to the occurrence of the phenomena. In the methodological conception, it is configured by the choice of the qualitative method, based on the deepening of the understanding of what is studied and the analysis of the results. In response, the study revealed that a process will favor quality to the extent that it has robust, welldeveloped, continuously developed self-regulatory mechanisms, with credibility with the academic community.

Palabras clave: Self-Regulation; Quality; Higher Education.

\section{Introdução}

Este estudo objetiva analisar os processos regulatórios e avaliativos de IES, vigentes em Portugal, por meio dos Sistemas Internos de Garantia da Qualidade (SIGQ), para assim, estabelecer proposições junto ao modelo Brasileiro, de modo a favorecer os processos de autorregulação.

\footnotetext{
${ }^{1}$ Pós Doutoranda - USP - Ribeirão Preto/SP. Email: julianasilvadias7@gmail.com

2 Prof. Adjunto III da Universidade Tiradentes, Aracaju. Email: cassius.gomes2@gmail.com
} 
É inegável que as práticas de autorregulação da Educação Superior, que visam mensurar e garantir a qualidade, influenciando nos modelos de funcionamento das Instituições de Ensino Superior (IES), têm assumido lugar de destaque nas pautas educacionais. Os governantes têm atribuído a estas práticas uma importante função, pois as consideram mecanismos capazes de organizar reformas necessárias e assegurar a oferta de uma educação de qualidade.

Entende-se, que a qualidade da educação é um fenômeno complexo e abrangente, que envolve muitas dimensões e, assim sendo, deve ser autorregulada de forma sistêmica e global, pois o sistema educacional é formado por múltiplos componentes que se inter-relacionam e se influenciam mutuamente. Acredita-se que a qualidade educacional deve ser sempre considerada em seu conjunto, medidas isoladas não surtirão efeito.

Processos autorreguladores, que objetivam aferir e garantir a qualidade educacional, precisam se pautar em monitoramentos e avaliações formativas, indo além do simples enquadramento de produtos. Avaliar e compreender os processos gerados, consiste em uma ação sistemática que busca a compreensão global da educação, pelo reconhecimento e pela integração de suas diversas dimensões, desconsiderando práticas pontuais e fragmentadas.

Assim, na busca pela identificação do campo a ser pesquisado e estudado, realizou-se uma pesquisa bibliográfica, por meio da qual foi possível identificar que se deveria realizar o estudo aqui considerado em Portugal, mais precisamente nas Universidades de Aveiro, Porto e Coimbra, e assim foi feito. A pesquisadora passou quatro meses, de julho a outubro de 2017, visitando as aludidas instituições, coletando dados e informações junto aos processos de avaliação e regulação.

A escolha do país de destino, Portugal, se deu por este possuir um sistema de regulação e avaliação da Educação Superior similar ao Brasileiro. Os sistemas de ambos os países perseguem o mesmo objetivo: a garantia da melhoria da qualidade e a prestação de contas (accountability) por meio de instrumentos de caráter complementares e equivalentes.

Já a escolha das Universidades de Aveiro, Porto e Coimbra, se deu em função dos resultados positivos que estas têm obtido em seus processos nos últimos anos, conforme descrito a seguir.

Antes, contudo, não se pode deixar de destacar, ao mencionar o êxito observado no cotidiano acadêmico de tais IES, a reforma do ensino europeu, por meio da Declaração de 
Bolonha, também chamada de "Tratado" ou "Processo" de Bolonha, firmada em 19 de junho de 1999, por 29 países. Assim, pode-se notar, no âmbito das IES aqui evidenciadas, a dinâmica de acesso aos estudantes do próprio continente e a promoção da mobilidade, tornando o ensino mais competitivo e favorecendo a internacionalização do mesmo.

A Universidade de Aveiro, instituída em 1973, é a mais jovem das três, mas já figura entre as melhores universidades do mundo, de acordo com o World University Rankings (CWUR ${ }^{3}$ ) de 2017. A qualidade da educação e da formação que é dada aos estudantes, o prestígio dos membros das faculdades e a qualidade e o impacto da sua pesquisa são alguns dos seus pontos fortes, que a colocam entre as 600 mais importantes e prestigiadas IES do mundo.

Fundada em 1911, a Universidade do Porto é uma instituição de ensino e investigação científica de referência em Portugal, figurando entre as melhores universidades europeias nos mais importantes rankings internacionais. Atualmente, a Universidade do Porto é a mais internacional das universidades portuguesas, fruto de uma estratégia que contempla laços de cooperação com centenas de IES dos quatro cantos do planeta. A ambição passa por afirmar a instituição entre as 100 melhores universidades do mundo até 2020.

Já a Universidade de Coimbra, desde 2016, por meio do QS World University Rankings by subject $^{4}$, voltou a estar entre a elite mundial das IES. Foi considerada a melhor universidade portuguesa nas áreas de Biological Sciences; Mathematics e Law.

Logo, a pesquisa de campo realizada junto as estas três renomadas universidades, possibilitou a identificação de alguns fatos que contribuíram para que atingissem, nos últimos três anos, os patamares de qualidade evidenciados anteriormente, e dentre estes destaca-se a institucionalização dos SIGQ, nas três IES aqui consideradas.

Buscou-se assim, conhecer as práticas de avaliação e regulação da Educação Superior portuguesa, que passam essencialmente pela implantação, institucionalização e certificação dos

\footnotetext{
${ }^{3} \mathrm{O}$ Centro de Rankings Universitários Mundiais (CWUR) publica os únicos rankings globais que avaliam a qualidade da educação, o emprego de ex-alunos, a qualidade da pesquisa e a inovação, sem depender de pesquisas e submissões de dados da universidade. Além de fornecer classificações universitárias globais autorizadas conhecidas por objetividade, transparência e consistência, a CWUR fornece serviços de consultoria a governos e instituições educacionais que aspiram a alcançar padrões de classe mundial.

${ }^{4} \mathrm{O}$ QS World University Rankings by Subject classifica as universidades do mundo em áreas individuais. Os rankings visam ajudar os potenciais estudantes a identificar as principais escolas do mundo no campo escolhido, com a lista de assuntos estendidos a cada ano em resposta para uma maior demanda por comparações de nível de assunto.
}

Periódico Horizontes - USF - Itatiba, SP - Brasil - e020074 
SIGQ, capazes de favorecer a autorregulação, visando a reflexão, o autoconhecimento e a tomada de decisão institucional

\section{Percurso metodológico}

Ao classificar esta pesquisa, considerando seu objetivo, vale ressaltar Gil (2007) quando explica que, com base nos objetivos, é possível classificar as investigações científicas em três grupos: exploratória, descritiva e explicativa.

Assim, tal pesquisa é caracterizada como exploratória, pois se preocupou em identificar os fatores determinantes, que contribuíram para a ocorrência dos fenômenos, ou seja, este tipo de pesquisa explica o porquê dos fatos por meio dos resultados oferecidos.

$\mathrm{Na}$ concepção metodológica, especificamente no que se refere ao procedimento de abordagem, esta pesquisa configura-se pela escolha do método qualitativo. Deste modo, não é centrada em representatividades numéricas, mas sim no aprofundamento da compreensão do que se estuda e da análise do resultado obtido. Sobre isso, Minayo (2001) enfatiza que a pesquisa qualitativa trabalha com o universo de significados, motivos, aspirações, crenças, valores e atitudes, o que corresponde a um espaço mais profundo das relações, dos processos e dos fenômenos que não podem ser reduzidos à operacionalização de variáveis.

A escolha de se enveredar por uma opção metodológica como a qualitativa neste estudo, justifica-se pelo interesse na realização de análises mais profundas que ultrapassem o limite da superficialidade e que possibilitem uma compreensão mais completa dos fatos e variáveis que tangenciam o objeto aqui investigado, a partir de uma perspectiva mais abrangente, com possibilidades explicativas e interpretativas, a fim de encontrar respostas coerentes e ajustadas a problemática apresentada. Sánchez (2012, p.44), coopera neste âmbito, afirmando que "A simples coleta e tratamento de dados não é suficiente, faz-se necessário resgatar a análise qualitativa para que a investigação se realize como tal e não fique reduzida a um exercício de estatística".

Desta forma, a conjugação e articulação de diferentes procedimentos de coleta de dados tornou-se imperativa, a fim de se obter resultados mais aprofundados, proporcionando ganhos relevantes para a complexidade das questões que envolvem a avaliação, bem como a autorregulação da Educação Superior. 
A articulação da pesquisa qualitativa em que se engendra este estudo caracteriza-se especialmente pela flexibilidade das técnicas utilizadas na coleta de dados. Com isso, foi possível a obtenção de dados mais relevantes e legítimos, que foram tratados indutivamente, de forma a revelar resultados pertinentes ao que se propôs no objetivo e ao longo do estudo.

Segundo Sánchez (2012, p.26): "Nos diferentes métodos e formas de abordar a realidade educativa, estão implícitos diferentes pressupostos que precisam ser desvelados". Assim, comenta-se sobre a coleta de dados utilizados na investigação e na obtenção de informações.

A pesquisa bibliográfica em questão, foi realizada com o intuito de identificar modelos/processos de avaliação e regulação da Educação Superior semelhantes ao brasileiro, e que pudessem servir de inspiração para elaboração de proposições, de modo a favorecer os processos de autorregulação, conforme objetivo deste estudo. Tal pesquisa se efetivou por meio da revisão de artigos publicados. De acordo com Fonseca (2002, p.32):

A pesquisa bibliográfica é feita a partir do levantamento de referências teóricas já analisadas, e publicadas por meios escritos e eletrônicos, como livros, artigos científicos, páginas de web sites. Qualquer trabalho científico inicia-se com uma pesquisa bibliográfica, que permite ao pesquisador conhecer o que já se estudou sobre o assunto.

Os critérios adotados para a seleção dos artigos foram os seguintes: artigos que descrevessem métodos, modelos ou estruturas de avaliação e regulação da Educação Superior, publicados em língua inglesa, entre janeiro de 2007 a janeiro de 2017. Justifica-se a opção pela língua inglesa, uma vez que se observou, ao iniciar a busca pelos artigos, que a maioria estavam publicados em tal idioma.

Já os critérios adotados para a exclusão dos artigos foram: artigos que não consideravam métodos, modelos ou estruturas de avaliação da Educação Superior, que não apresentavam de forma clara e completa a metodologia utilizada.

A busca ocorreu com base nas seguintes questões norteadoras: Quais são os modelos/processos de avaliação e regulação utilizados para verificar a qualidade da Educação Superior? Como são os instrumentos considerados nestes processos? Qual é a relevância de tais mecanismos para o aprimoramento da qualidade da Educação Superior? 
Para tanto, utilizou-se uma lista de palavras-chave, a saber: internal evaluation, higher education, perceptions, opinion, quality evaluation, college, university, post secondary, course evaluation, students perception, instruments, tools. E como estratégia de pesquisa para combinação das palavras chave foram utilizados "AND" e "OR".

A estratégia de busca utilizada foi, como segue: ("internal evaluation") AND ("higher education OR college OR university OR post secondary OR postsecondary") AND (perceptions OR opinion) AND ("quality evaluation") AND ("higher education") AND (instruments OR tools).

A pesquisa em questão respeitou a temporalidade definida no intervalo de tempo compreendido entre janeiro de 2007 a janeiro de 2017. Os artigos foram selecionados inicialmente por meio da leitura de títulos, resumos e metodologia. Uma vez atendidas as questões de pesquisa, e os critérios estabelecidos, os artigos relevantes foram selecionados e procedeu-se a leitura dos mesmos.

A pesquisa identificou 1244 papéis, após a primeira triagem. Foram excluídos 720 artigos, ficando 524, destes foram selecionados 112, e finalmente chegou-se aos 41 artigos, que foram lidos na íntegra.

O processo de exclusão iniciou-se por meio da retirada da base de análise de artigos duplicados. Em seguida foi observado se aqueles selecionados apresentavam, em seus títulos e resumos, indícios referentes as questões norteadoras, assim, aqueles que não estavam relacionados essencialmente com a avaliação da Educação Superior, foram excluídos. Um terceiro processo de filtragem se deu por meio da identificação do percurso metodológico, no qual aqueles artigos que não apresentavam de forma clara a metodologia adotada também foram excluídos.

De 112 artigos que estavam prontos para revisão de texto completo, 71 ainda foram excluídos porque não dispunham de informações suficientes sobre modelos e métodos de avaliação e regulação da Educação Superior, ou tratavam de forma generalizada.

Já a pesquisa documental realizada, teve como objetivo analisar documentos legislativos considerados nos processos de avaliação e regulação desenvolvidos no Brasil e em Portugal, buscando identificar pontos convergentes e divergentes.

Conforme esclarece, Fonseca, (2002, p.32): 
A pesquisa documental trilha os mesmos caminhos da pesquisa bibliográfica, não sendo fácil por vezes distingui-las. A pesquisa bibliográfica utiliza fontes constituídas por material já elaborado, constituído basicamente por livros e artigos científicos localizados em bibliotecas. A pesquisa documental recorre a fontes mais diversificadas e dispersas, sem tratamento analítico, tais como: tabelas estatísticas, jornais, revistas, relatórios, documentos oficiais, cartas, filmes, fotografias, pinturas, tapeçarias, relatórios de empresas, vídeos de programas de televisão etc.

Desta forma, a pesquisa documental aqui realizada, foi pautada em documentos legais relacionados a regulação e avaliação da Educação Superior, como decretos, leis e portarias. A pesquisa efetivada por meio de tais documentos contribuiu para a melhor compreensão do tema de estudo e favoreceu o entendimento de particularidades a ele relacionadas. Salienta-se que, o valor do uso de documentos em pesquisas se deve à quantidade de informações que deles se pode extrair.

Para tanto, documentos foram identificados, decompostos e estudados. Appolinário (2009, p.67), define documentos como sendo: "Qualquer suporte que contenha informação registrada, formando uma unidade que possa servir para consulta, estudo ou prova". A pesquisa documental aqui ressaltada, muito contribuiu com o desenvolvimento deste estudo, uma vez que, de acordo com Sánchez (2012, p.167) “Os fenômenos educativos por sua natureza social se tornam também históricos, e, nesse sentido, é que se supõe que toda investigação em educação trabalhe necessariamente com a historicidade".

Enfatiza-se que, as etapas de identificação, decomposição e análise dos documentos, favoreceu a produção e a (re) elaboração de conhecimentos, criando novas formas de se perceber e compreender o objeto estudado. Contudo, May (2004) afirma que os documentos não existem isoladamente, precisam ser situados em uma estrutura teórica para que o seu conteúdo seja entendido. Destarte, esta pesquisa considerou caracterizações, definições, aspectos legais e conjecturas educacionais como base teórica para a análise proposta.

De acordo com Oliveira (2007), a pesquisa documental, exige do pesquisador uma análise criteriosa, em geral baseada em conteúdo, visto que os documentos ainda não passaram por nenhum tratamento científico. De acordo com Apolinário (2009, p.27), pode-se entender como sendo análise de conteúdo: 
Conjunto de técnicas de investigação científicas utilizadas em ciências humanas, caracterizadas pela análise de dados linguísticos. [...]. Normalmente, nesse tipo de análise, os elementos fundamentais da comunicação são identificados, numerados e categorizados. Posteriormente as categorias encontradas são analisadas face a uma teoria específica.

Consequentemente, a análise de conteúdo foi o mecanismo utilizado para interpretar os documentos analisados. De acordo com Bardin (2009, p.121), as diferentes fases da análise de conteúdo organizam-se em torno de três polos: “1. A pré análise; 2. A exploração do material; e, por fim, 3. O tratamento dos resultados: a inferência e a interpretação".

Assim caracterizando cada um destes polos, a partir deste estudo tem-se:

1. Pré análise: momento em que foram identificados os documentos legais. Este processo considerou previamente o tema abordado em cada um dos documentos.

2. Exploração do material: por conseguinte, foi empregado o Web Qualitative Data Analysis, WebQDA 5 (um software de análise de dados qualitativos). Explica-se que, a utilização do WebQDA, deve-se ao fato de que indagar é tarefa basilar para fazer ciência e que o pesquisador precisa desenvolver o pensamento crítico por intermédio de questionamentos nas várias fases da pesquisa. Isso posto, argumenta-se que estes questionamentos são mais eficientes quando sustentados por artefatos tecnológicos, como as existentes no WebQDA.

3. O tratamento dos resultados, a inferência e a interpretação: os resultados obtidos foram organizados e tratados.

Neste âmbito, destaca-se que o WebQDA é um software capaz de auxiliar pesquisadores desde a fase da coleta de dados, até a fase de redação das considerações finais. Por meio da sua utilização o pesquisador pode editar, visualizar, interligar e organizar documentos e informações.

Chizzotti (2006) comenta que um texto contém sentidos e significados que podem ser apreendidos pelo leitor que interpreta a mensagem nele contida por meio de técnicas metódicas. Logo, a mensagem pode ser apreendida decompondo-se o conteúdo do documento em fragmentos mais simples, que revelem sutilezas contidas no texto. Os fragmentos podem ser palavras, termos ou frases significativas de uma mensagem, que poderão favorecer o

${ }^{5}$ www.webqda.com

Periódico Horizontes - USF - Itatiba, SP - Brasil - e020074 
entendimento dos fatos a partir do contexto em que estão postos.

Ludke e André (1986) ponderam que existem dois tipos de unidade de análise: a unidade de registro e a unidade de contexto, ambas utilizadas neste estudo.

$\mathrm{Na}$ unidade de análise foram selecionados segmentos específicos do conteúdo, por exemplo, a frequência com que aparece no texto uma determinada palavra, um tópico, um tema ou uma expressão. No entanto, em função dos objetivos, explorou-se também o contexto, além da citada frequência. Assim, o método de codificação escolhido respeitou a natureza do problema, do arcabouço teórico e das questões específicas.

Assim, após a realização da pesquisa bibliográfica que possibilitou a escolha do campo de estudo, partiu-se para a efetivação da pesquisa de campo, com o intuito de observar, coletar, analisar e interpretar fatos capazes de favorecer o atendimento do objetivo deste estudo. Pois, conforme aponta JOSÉ, F. M., (2006, p.64): “[...] o ato de pesquisar traz em si a necessidade do diálogo com a realidade a qual se pretende investigar e com o diferente, um diálogo dotado de crítica, canalizador de momentos críticos". A tentativa de conhecer qualquer fato constituinte dessa realidade busca uma justaposição, visto sua complexidade e dinâmica.

A partir desta perspectiva, Gonçalves (2001, p.67), aponta que:

A pesquisa de campo é o tipo de pesquisa que pretende buscar a informação diretamente com a população pesquisada. Ela exige do pesquisador um encontro mais direto. Nesse caso o pesquisador precisa ir ao espaço onde ocorre o fenômeno, ou ocorreu e reunir um conjunto de informações a serem documentadas [...].

Conforme já posto, após identificação do campo a ser estudado, efetivou-se a pesquisa de campo junto as Universidade de Aveiro, do Porto e de Coimbra. A pesquisa realizada junto as estas três renomadas universidades, possibilitou conhecer melhor as práticas de avaliação e regulação adotadas. Para tanto realizou-se também entrevistas semiestruturadas, com gestores da área em cada uma das três instituições citadas.

Buscou-se, assim, conhecer de forma mais aprofundada o sistema de avaliação e regulação da Educação Superior portuguesa. Entrevistou-se, além dos responsáveis pelos processos de auto avaliação nas citadas Universidades, o presidente do conselho administrativo da A3ES. 
Logo, a técnica de entrevistas semiestruturadas, foi utilizada e contou com roteiros previamente elaborados. Para Triviños (1987, p.146):

[...] a entrevista semi-estruturada tem como característica questionamentos básicos que são apoiados em teorias e hipóteses que se relacionam ao tema da pesquisa. Os questionamentos dariam frutos a novas hipóteses surgidas a partir das respostas dos informantes. O foco principal seria colocado pelo investigador-entrevistador.

Complementa o autor, afirmando que a entrevista semiestruturada, Triviños (1987, p.152): "[...] favorece não só a descrição dos fenômenos sociais, mas também sua explicação e a compreensão de sua totalidade [...] além de manter a presença consciente e atuante do pesquisador no processo de coleta de informações".

Neste sentido destaca-se que as técnicas de entrevista semiestruturada possibilitaram uma maior interação entre o entrevistador e o entrevistado, favorecendo respostas mais espontâneas, o que consente ao entrevistador tocar em assuntos mais complexos. As respostas espontâneas e a liberdade, aumentam a probabilidade de surgirem questões inesperadas que poderão ser muito úteis na pesquisa.

\section{Autorregulação na educação superior, amparada em sistemas internos de garantia de qualidade}

Atualmente, no Brasil, uma relevante questão, especialmente junto a Educação Superior, tem sido o debate sobre a autorregulação. O modelo, cada vez mais presente em diversas atividades e segmentos, apresenta-se eficiente, contribuindo para avanços no desenvolvimento de todo o mercado, com maior segurança e estabilidade.

A autorregulação das IES tem sido um dos temas em pauta no Ministério da Educação (MEC), e neste contexto vale destacar o entendimento de que autorregulação da Educação Superior não se resume e nem é sinônimo de desburocratização e, portanto, não deve se iniciar por este meio.

Considerando tais aspectos, e a partir de pesquisa bibliográfica realizada no âmbito da autorregulação, destaca-se que neste estudo, compreende-se a autorregulação como um 
processo consciente, consistente e espontâneo de governo, por meio do qual se torna possível gerenciar os próprios comportamentos, pensamentos, ações, decisões, de forma cíclica, visando o alcance de metas e conduzidos por padrões de conduta, tal compreensão está amparada em Bandura; Azzi ePolydoro (2008, p.151).

Ainda vale destacar que se admite que a autorregulação trata de um fenômeno multifacetado, que opera por meio de processos cognitivos subsidiários, incluindo automonitoramento, julgamentos autoavaliativos e autorreações, de acordo com Bandura, (1991).

Logo, simplificá-lo como sendo o fim da burocratização da Educação Superior, não faz sentido. É sabido que em países onde as IES se autorregulam, a necessidade de intervenção do Estado é naturalmente menor, mas tal fato só se torna possível após resultados positivos observados, refletidos em organização e garantias de qualidade, comprovadamente obtidos por meio de processos autorregulatórios responsáveis, bem definidos e institucionalizados.

Somente a partir daí se torna possível reduzir a burocracia atualmente imposta à Educação Superior brasileira, onerando menos o Estado e conjecturando ganhos para a população. Acredita-se, que por meio do desenvolvimento e consequente amadurecimento dos processos de autorregulação, os governos poderão cada vez mais se afastarem do modelo de controle atualmente adotado, abdicando das tentativas de regular todos os aspectos do sistema educacional e transferindo decisões e responsabilidades para as próprias instituições.

Assegura-se que os processos de autorregulação, devem sim ser estabelecidos pelas próprias IES, que devem também receber certificação, seja por meio de agências de acreditação ou do próprio MEC, e trilhar um desenvolvimento sustentado na busca pela garantia de qualidade.

Deve-se ainda enfatizar que independente da autorregulação, cabe ao MEC a definição de políticas públicas e direcionamentos a respeito da Educação Superior brasileira. Cabe destacar preliminarmente o papel do MEC em sua missão de autorizar e avaliar as instituições e cursos de graduação, conforme estabelece o art. 209 da Constituição Federal, tratando-se de reserva legal absoluta de competência nela preceituada.

Na busca por indicar a importância e a necessidade do desenvolvimento de processos de autorregulação na Educação Superior, destaca a autorregulação na perspectiva sociocognitiva, 
enfatizando a capacidade do homem de intervir intencionalmente em seu ambiente, de forma a vislumbrar e escolher cursos de ação que julgarem mais convenientes ou necessários.

Nota-se que a autorregulação não é um processo isolado. Logo, explicita-se que este estudo considera a autorregulação um importante caminho a ser trilhado pela Educação Superior brasileira, entendendo que este mecanismo favorece a percepção das próprias potencialidades e fragilidades ao longo do cotidiano acadêmico, no desígnio de se alcançar resultados proeminentes e garantir a qualidade da educação ofertada.

Sopesando que o "sucesso acadêmico é um conceito multidimensional, caracterizado de acordo com o contexto social e que abrange diferentes aspectos [...]", conforme aponta Silva, (2013, p.350), e tendo em vista que o desempenho e sucesso acadêmico são processos complexos, torna-se necessário estudar meios de se promover a autorregulação institucional, incentivando que as IES reavaliem cotidianamente suas vidas acadêmicas, refletindo sobre a maneira com que se organizam.

Desta forma, a autorregulação pode ser considerada como sendo um processo auto diretivo, relacionada ao auto ajustamento institucional, visando atender às demandas da vida acadêmica. O desconhecimento ou a não observação das próprias características institucionais, e de suas potencialidades e fragilidades pode acarretar o não atendimento ou na inadequação às exigências acadêmicas. Segundo Bandura; Azzi e Polydoro (2008, p.151),

[...] a autorregulação é vista como um mecanismo interno consciente e voluntário de controle, que governa o comportamento, os pensamentos e os sentimentos pessoais tendo como referência metas e padrões pessoais de conduta a partir dos quais se estabelece consequências para o mesmo.

Um pressuposto fundamental de todo processo de autorregulação institucional, é o do respeito pela autonomia das IES. Assim, destaca-se que os procedimentos não se debruçam diretamente sobre o desempenho da instituição, mas sim na forma como são definidos a sua missão, seus objetivos, planos operacionais e resultados alcançados.

O objeto da autorregulação tem a ver com a estratégia institucional para a qualidade e o modo como a mesma se traduz, neste estudo acredita-se que tal objeto deve estar materializado em um SIGQ eficaz e bem documentado. A autorregulação incide, por conseguinte, sobre os processos e procedimentos de promoção e garantia da qualidade. 
No intuito de favorecer o desenvolvimento de SIGQ nas IES, de identificar e desenvolver boas práticas no domínio da garantia da qualidade, e sobretudo considerando as informações coletadas por meio das entrevistas semiestruturadas realizadas no campo de pesquisa deste estudo, entende-se como objetivos específicos do processo de autorregulação:

- $\quad$ Possuir uma Política Institucional para a Qualidade e apreciar se a sua implementação contempla, de forma clara e objetiva, a definição, objetivos, funções e fatores do SIGQ, bem como a definição e organização dos níveis de responsabilidades que a eles estão associados.

- Avaliar os processos e procedimentos utilizados pela instituição para a manutenção e melhoria da qualidade do ensino e demais atividades praticadas.

- Avaliar até que ponto o SIGQ funciona de acordo com os procedimentos instituídos, produz informações úteis e relevantes para a melhoria da instituição, e utiliza essas informações para gerar medidas efetivas para a melhoria contínua da qualidade das atividades desenvolvidas e respectivos resultados.

Assim, a autorregulação considerada neste estudo tem por objeto o SIGQ, e se baseia em diagnósticos, pressupostos e interesses, que incidem sobre os procedimentos de garantia da qualidade associados às diferentes vertentes da missão institucional, dos objetivos dos cursos ofertados e das áreas transversais que dão suporte, bem como sobre a articulação do SIGQ com os mecanismos de gestão estratégica da instituição. Tais bases foram observadas nas três instituições portuguesas consideradas nesta pesquisa, revelando total pertinência e estreita correlação com a busca pela garantia da qualidade institucional por meio da autorregulação.

\section{Sistemas Internos de Garantia de Qualidade (SIGQ)}

Tendo como referência as renomadas Universidades de Aveiro, Porto e Coimbra, bem como as entrevistas realizadas no âmbito de tais instituições, constatou-se a relevância que, atualmente, os SIGQ possuem no cotidiano acadêmico português, bem como teve-se acesso a documentos que asseguram as bases sob as quais os SIGQ estão consolidados. E foi assim, por meio dessa relevante experiência, que se estabeleceu a proposição que nesta subseção se apresenta: a implantação, pelas IES brasileiras, de sistemas internos de garantia de qualidade 
como pilar de sustentação dos processos de autorregulação.

Mas, entende-se como necessário, antes de mais nada, enfatizar que o modelo de avaliação e regulação da Educação Superior brasileiro, atualmente vigente, tem como bases legais, dentre outras a Lei no 10.861 de 14 de abril de 2004, que instituiu o Sistema Nacional de Avaliação da Educação Superior - Sinaes e o Decreto no 9235, de 15 de Dezembro de 2017, que por sua vez dispõe sobre o exercício das funções de regulação, supervisão e avaliação das IES e dos cursos superiores de graduação e de pós-graduação no sistema federal de ensino.

Ao se considerar e analisar os mecanismos legais citados anteriormente, comenta-se que nenhum deles favorece processos de autorregulação, enfatizam no máximo a relevância do desenvolvimento de mecanismos autoavaliativos. E neste âmbito, entende-se que o sistema educacional brasileiro precisa avançar, induzindo de forma responsável as práticas autorreguladoras, a busca pela garantia da qualidade, sempre pautando em um pressuposto chave, o de que a responsabilidade pela qualidade dos serviços prestados é, antes de mais nada, das próprias instituições.

Posto tais aspectos, apresenta-se as relevantes características dos três SIGQ pesquisados e seus impactos no processo de consolidação da cultura da qualidade educacional.

\section{Universidade do Porto (U.Porto) e seu Sistema Interno de Garantia de Qualidade (SIGQ)}

O nível organizacional do SIGQ da U.Porto assegura a disponibilização de conteúdos informativos de natureza transversal a toda a comunidade acadêmica, bem como o acesso a recursos e serviços de suporte ao funcionamento da Universidade.

Através da pesquisa de campo e das entrevistas semiestruturadas realizadas, foi possível constatar que, nos últimos dez anos, a U.Porto avançou na formalização do seu SIGQ. Conforme apontado pelo gestor entrevistado "O nível organizacional do Sistema de Informação SIGARRA assegura a disponibilização de conteúdos informativos de natureza transversal a toda a comunidade da U.Porto, bem como o acesso a recursos e serviços de suporte ao funcionamento interno, de acesso restrito da Universidade".

O sistema em questão não objetiva apenas a vertente ligada aos procedimentos de controle e de verificação de conformidades, mas também as rotinas de avaliação e melhoria, fato 
que foi identificado como um importante diferencial dentro da estrutura organizacional.

Como marco inicial deste processo de consolidação da cultura da qualidade, cita-se o ano de 2006, momento em que a U.Porto institucionalizou o Serviço de Melhoria Contínua, atualmente Gabinete de Estudos Estratégicos e Melhoria Contínua, que tem por missão, Portugal (2016d): "elaborar estudos que contribuam para a promoção da qualidade do ensino e investigação". E como vertentes, Portugal, (2016d): planear, apoiar e controlar um SIGQ inclusivo, no qual todos os colaboradores da U.Porto sejam atores da qualidade, independentemente de onde e quando realizem o seu trabalho. Através de procedimentos simples, integrar nas tarefas correntes os mecanismos de avaliação e de melhoria e promover a cultura da qualidade.

A consolidação de uma cultura institucional voltada para a qualidade foi assumida como elemento estratégico na Gestão da U.Porto, como se pode confirmar nos sucessivos planos estratégicos e grandes linhas de ação disponibilizados ${ }^{6}$.

Em 2017 (ano em que a pesquisa de campo, efetivada por meio deste estudo, foi realizada) a U.Porto solicitou à A3ES auditoria junto ao seu SIGQ, que foi certificado por seis anos, revelando, assim, a sua consistência e nível de excelência naquilo que se propôr a fazer.

\section{Universidade de Aveiro (UA) e seu Sistema Interno de Garantia de Qualidade (SIGQ)}

$\mathrm{Na}$ busca pela consolidação de uma cultura da qualidade institucional, a UA desenvolveu um modelo de referência para a qualidade, considerando os vetores da sua missão. Institucionalizou a sua política para a garantia da qualidade, que procura promover de forma transversal na instituição a participação ativa e empenhada de cada um dos seus membros no aprofundamento da cultura da qualidade, por meio do seu comprometimento e contribuindo para a melhoria contínua de cada um dos processos em que intervêm, tais fatores foram evidenciados por meio da realização de pesquisa de campo e de entrevistas semiestruturadas.

Ainda de acordo com os fatos corroborados na pesquisa de campo e entrevistas,

\footnotetext{
${ }^{6}$ Disponível em: https://sigarra.up.pt/up/pt/web_base.gera_pagina?p_pagina=1001375 
conforme evidenciado no Manual da Qualidade da $U A^{7}$, destaca-se que o seu organograma contempla três componentes fundamentais, a saber, Portugal (2016b, p.9):

Central: onde os Vice-Reitores e Pró-Reitores, responsáveis pelas áreas nucleares da missão da UA, estabelecem a estratégia institucional e os padrões de qualidade, através da identificação dos objetivos operacionais, ações, indicadores e metas. Local em que as ações a desenvolver contêm as que resultam da desagregação da estratégia institucional, e são implementadas ao nível das estruturas funcionais da Universidade. A fórmula organizativa que cada uma destas estruturas adota pode variar, em razão até do seu regulamento interno, mas todas elas têm um 'Pivot para a Qualidade' que é o elemento de contacto na operacionalização e gestão do SIGQ_UA;

De apoio à gestão e à operacionalização do SIGQ_UA: em particular nas ações que envolvem a interação entre as componentes Central e Local, promovendo o bom funcionamento do sistema e tendo atenção especial, também, ao monitoramento e a correção do seu funcionamento.

Para além desta estrutura apresentada, enfatiza-se a participação nos processos de garantia da qualidade dos Órgãos da Fundação e de Governo da UA, que integram membros externos designadamente na homologação e aceitação dos seus documentos estratégicos. A presença do "Fórum para a Qualidade" no organograma corresponde à identificação de uma necessidade de apoio estrutural adicional que dê um suporte formal, com valor acrescentado, na ligação entre a componente Central e Local na gestão do SIGQ_UA.

A UA, ainda se diferencia por meio do seu Manual da Qualidade, segundo o gestor entrevistado:

O Manual da Qualidade é o documento que descreve o Sistema Interno de Garantia da Qualidade da Universidade de Aveiro, a forma como está organizado, os atores internos e externos envolvidos e os procedimentos para a garantia da qualidade da atividade da instituição. Neste sentido, o manual em questão consubstancia, do ponto de vista formal, o conjunto de práticas que há vários anos tem sido levado a cabo pela instituição no sentido do cumprimento da política institucional para a garantia da qualidade instituída e da melhoria contínua da sua atividade nas várias áreas nucleares da missão, em alinhamento com os termos de referência nacionais e europeus para a qualidade institucional.

\footnotetext{
${ }^{7}$ Documento que descreve o Sistema Interno de Garantia da Qualidade da Universidade de Aveiro (SIGQ_UA) - o âmbito, a forma como está organizado, os atores internos e externos envolvidos e os procedimentos para a garantia da qualidade da atividade da instituição. Disponível em: https://www.ua.pt/sigq/page/22105
}

Periódico Horizontes - USF - Itatiba, SP - Brasil - e020074 
Impressiona, positivamente, o fato de se verificar, junto aos profissionais que atuam na UA, a preocupação com a qualidade institucional, que já em seu organograma se materializa na forma de um sistema de garantia da qualidade capaz de assegurar o planeamento, o monitoramento, avaliação e (re)avaliação, bem como a melhoria contínua das atividades, assim como o alinhamento das novas iniciativas com a estratégia institucional, envolvendo nesse processo todos os órgãos e interlocutores relevantes.

\section{Universidade de Coimbra (UC) e seu Sistema Interno de Garantia de Qualidade (SIGQ)}

A Universidade de Coimbra adota, em todas as áreas de atuação, práticas baseadas em sistemas de gestão da qualidade, devidamente aferidos e avaliados segundo padrões reconhecidos internacionalmente, esta constatação se deu por meio de entrevistas realizadas. Conforme informado pelo gestor entrevistado:

A Universidade de Coimbra tem vindo a consolidar o seu sistema de gestão através da definição anual de um plano de qualidade, alinhado com o Plano Estratégico da instituição e com o Plano de Ação dos seus vários setores. É dada uma atenção especial à atualização e melhoria de procedimentos e ao resultado das diversas auditorias internas e outros exercícios de autoavaliação de todas as unidades e serviços, com vista à melhoria contínua.

O Sistema de Gestão da Universidade de Coimbra - SG.UC - é uma ferramenta de apoio à gestão integrada da Instituição, que assegura a implementação de uma estratégia institucional voltada para a qualidade e adequada às suas especificidades, e que contempla o conjunto de todos os processos, documentos, sistemas de informação e outros instrumentos de apoio ao planeamento, execução, monitoramento, (re)avaliação e melhoria contínua das atividades desenvolvidas na Universidade. Tem como objetivo a promoção de uma cultura de qualidade, com vista à satisfação global das diferentes partes interessadas e à excelência da instituição em todas as áreas de atuação.

Conforme, explícita o Manual do Sistema de Gestão da Universidade de Coimbra, Portugal $^{8}$ (2016c, p.4): "a Universidade de Coimbra, está focalizada na promoção de uma cultura

\footnotetext{
${ }^{8}$ Disponível em: https://www.uc.pt/damc/manual/manual_sistema_gestao_15 
de qualidade transversal a todas as unidades/serviços, com vista à melhoria contínua dos seus processos e à satisfação das necessidades e expectativas das suas partes interessadas [...]".

Para tanto, a UC, dispõe de uma política de qualidade, conforme verificada por meio de pesquisa de campo, aprovada em setembro de 2015, estruturada em sete linhas que indicam o compromisso da instituição com vista a melhoria contínua, conforme pode-se constatar no Manual do Sistema de Gestão da Universidade de Coimbra, Portugal, (2016c, p.14):

1. Fomentar o envolvimento de toda a comunidade acadêmica, nomeadamente dos estudantes, numa estratégia de diferenciação pela qualidade, assegurando a eficácia do Sistema de Gestão da Qualidade.

2. Viver a UC como universidade europeia de referência onde conhecimento e inovação se constroem, numa aliança orientada para os novos desafios societais, abrindo ao mundo um patrimônio e tradições centenárias.

3. Garantir a qualidade e melhoria contínua do ensino e da oferta formativa, alinhando as competências dos estudantes com as exigências da formação avançada e do mercado de trabalho.

4. Reforçar a ligação Ensino - Investigação - Transferência (s) de conhecimento, promovendo a colaboração entre a Universidade e o tecido econômico, social e cultural.

5. Dotar a UC das mais avançadas formas de serviços especializados à comunidade, valorizando o conhecimento, o desenvolvimento econômico e social e a inovação.

6. Fomentar o comprometimento entre a organização e os trabalhadores, promovendo a comunicação interna participada e o reforço de competências individuais.

7. Fomentar a gestão sustentável de recursos, o bem-estar das pessoas e a responsabilidade social da organização.

Para assegurar, a efetividade da sua política de qualidade, por meio do seu SG.UC, destaca-se o seu organograma, estrutura que carrega em si a preocupação com a qualidade dos serviços prestados, Portugal, (2016c, p.24):

O Conselho da Qualidade: assegura a gestão estratégica do SG.UC. É nomeado pelo Reitor, que o preside;

Gestão do Topo: responsável por cumprir e fazer cumprir a estratégia para a qualidade na UC;

Divisão de Avaliação e Melhoria Contínua e Gestor da Qualidade: integrados na administração da UC, asseguram a coordenação funcional e global do SG.UC, acompanhando de forma transversal a implementação da estratégia para a qualidade na UC;

Dinamizadores da qualidade: são técnicos que prestam apoio ao dirigente da 
unidade/serviço no âmbito das atividades que contribuem para a promoção de uma cultura de qualidade na UC;

Auditores internos da qualidade: participam dos processos de auditorias internas da qualidade, integradas no Programa de Auditorias que é aprovado pelo representante da gestão, visando a consolidação e melhoria do SC.UC.

Ainda cabe destacar a preocupação com as ações de monitoramento, análise e avaliação, todas integradas aos processos de planejamento e melhoria. A UC dispõem de um conjunto de mecanismos de medição do desempenho do SG.UC e dos seus processos organizados em dois níveis, estratégico e operacional. Então, pode-se constatar que todos estes processos são complementares e dão contribuições valiosas para os processos de melhoria contínua.

\section{Quanto a proposição - Sistema Interno de Garantia de Qualidade (SIGQ)}

Foi por meio de informações coletadas, em especial por meio da pesquisa de campo e das entrevistas semiestruturadas, conforme já relatado, que se elaborou a proposição de implantação nas IES brasileiras dos SIGQ, como pilar para consagração dos processos de autorregulação.

Assim, propõe-se que os mecanismos de (re)avaliação interna sejam suportados por SIGQ, devidamente institucionalizados, passíveis de certificação pelos órgãos reguladores e, sobretudo, pautados no princípio fundamental de que a qualidade, assim como a sua garantia são de responsabilidade, em primeiro lugar, das próprias IES.

Espera-se que tais sistemas sejam capazes de favorecer ações de monitoramento das atividades desenvolvidas pelas IES e seus cursos. Tudo isso de forma dinâmica e diversificada, respeitando e valorizando as particularidades, as diferenças e propiciando a auto formação, o autoconhecimento e a autorregulação institucional.

Nesta proposição, os SIGQ são entendidos como instrumentos essenciais para o aprimoramento dos serviços prestados. Vale ressaltar que a proposta é abrangente, e, portanto, não basta desenvolver e implantar o SIGQ, compete a cada IES definir e institucionalizar a sua política para a qualidade, criando rotinas de auto avaliação e auto monitoramento inclusive do próprio SIGQ. Para assim, favorecer o desenvolvimento e a garantia de uma cultura da qualidade, por meio de ações cotidianas como:

- Avaliar os processos e procedimentos utilizados pela instituição para a manutenção e 
melhoria da qualidade do ensino e demais atividades praticadas.

- Avaliar até que ponto o SIGQ funciona de acordo com os procedimentos instituídos, produz informações úteis e relevantes para a melhoria da instituição e dos seus cursos, e utiliza essas informações para gerar medidas efetivas para a melhoria contínua da qualidade das atividades desenvolvidas e respectivos resultados.

Como o objetivo de contribuir com os processos de implantação dos SIGQ, conforme proposto, e tendo como referência os resultados obtidos por meio da pesquisa de campo e de entrevistas realizadas em IES portuguesas, ressalta-se a importância de se definir referenciais de qualidade. Neste sentido, destaca-se a acuidade de se adotar uma política para a garantia da qualidade. A instituição deverá consolidar uma cultura voltada para a qualidade, apoiada numa política e em objetivos de qualidade formalmente definidos e publicamente disponíveis.

Assim, a estratégia institucional para a melhoria contínua será traduzida na prossecução de determinados objetivos de qualidade, configurando como parte integrante da gestão estratégica da instituição e contribuindo para a prestação de contas à sociedade.

\section{Mecanismos de garantia interna da qualidade institucional}

Entendendo que mesmo antes do atual conceito de garantia de qualidade associado à massificação da Educação Superior, e avaliando até mesmo períodos que se configuraram por meio de sistemas elitistas, considera-se que as IES brasileiras em seu cotidiano, já estabelecem padrões de qualidade.

De acordo com a interpretação atual deste conceito, pode-se afirmar que o compromisso de uma IES com a cultura da qualidade é um avanço neste processo de implantação de SIGQ, e agrega valor a busca pela oferta qualificada dos serviços educacionais.

Esta busca, que deve ser contínua, configura uma ação institucionalizada na rotina das IES, atribuindo caráter formal ao processo de garantia de qualidade. Assim, os gestores terão respaldo no que diz respeito as indicações e proposições de melhorias, como por exemplo indicativos da necessidade de reforço do planeamento estratégico, da definição explícita dos padrões fundamentais de responsabilização externa, éticos e profissionais, e da adoção de um modelo contagiante na demanda de melhoria de qualidade. 
Nota-se a necessidade do desenvolvimento de um sistema de informação integrado, com o objetivo de facilitar o acesso à informação relevante de carácter pedagógico, científico, técnico e administrativo, e de dinamizar a colaboração interna e externa, com uma presença forte na Web, assim justifica-se a implantação e institucionalização de SIGQ. Compreende-se, que tais sistemas contribuirão e muito para a formalização da autorregulação no Brasil, de forma efetiva, formal e qualificada, com respaldo técnico e teórico.

Defende-se aqui, que a implantação, por parte de todas as IES, dos seus SIGQ, deve se tornar um dos pilares do sistema de autorregulação brasileiro, pois contribuirá para a normalização de rotinas e de procedimentos, para a estabilização de boas práticas e para a sistematização de mecanismos de recolha, análise e divulgação de indicadores de ensino (acessos, estudantes inscritos, diplomados, egressos, internacionalização e empregabilidade), pesquisa, extensão, recursos humanos e demais aspectos que se fizerem necessário.

O desenvolvimento do SIGQ será mola propulsora para impulsionar a criação de serviços de melhoria contínua, concebendo e apoiando um sistema inclusivo, capaz de envolver todos os colaboradores e que integre os mecanismos de avaliação e melhoria nas tarefas corrente, encetando um novo e ambicioso processo de avaliação institucional.

Assim registra-se que, apesar dos importantes progressos alcançados ao nível da transparência e da "accountability", ainda persistem algumas debilidades e insuficiências que, em parte se devem à pouca formalização dos processos de auto avaliação nas IES brasileiras.

A reflexão subsequente conduz à necessidade de consolidação das bases de um SIGQ, cujo desenvolvimento diz respeito aos procedimentos de monitoramento e avaliação de cursos e IES, reforçando o papel dos respetivos gestores e das suas comissões científicas e de acompanhamento. Em simultâneo, deve-se desenvolver módulos para este efeito no SIGQ, que busca simplificar o trabalho de monitoramento e de avaliação da qualidade e permitir uma comparabilidade transversal na IES, junto à comunidade acadêmica.

Como resultado deste trabalho, pode-se afirmar que a cultura da qualidade institucional é um dos elementos estratégicos na gestão de qualquer IES e que os procedimentos de garantia da qualidade devem estar embebidos, e até se confundirem, com os procedimentos adotados de gestão e operacionais, contribuindo, a par do SIGQ, para o designado modelo, que deve ser contagiante na demanda de melhoria contínua de qualidade. 


\section{Caracterização do Sistema Interno de Garantia da Qualidade}

Como resultado das pesquisas realizadas, que gerou dados, informação e conhecimento, que favoreceu a elaboração deste estudo, já se destaca que a IES deverá elaborar, implantar e institucionalizar o manual da qualidade ou documentação equivalente sobre a definição e a operacionalização da política institucional para a qualidade.

Apesar do compromisso com a qualidade estar tacitamente assumido desde longa data nas IES brasileiras por meio da legislação tanto passado como presente, entende-se que se faz necessário a efetivação de passos importantes para a estabilização e formalização daquilo que, habitualmente, será designado por um SIGQ.

O SIGQ deve contemplar não só a vertente ligada aos procedimentos de controle e de verificação de conformidades, mas também que consagre rotinas de avaliação e melhoria. A exemplo disso, destaca-se que a UP, por meio da última revisão do regulamento orgânico da reitoria, publicado em Diário da República a 19 de agosto de 2016 (2016a), transformou o então Serviço de Melhoria Contínua, criado em 2006, no Gabinete de Estudos Estratégicos e Melhoria Contínua (GEEMC), que tem por missão "elaborar estudos que contribuam para a promoção da qualidade do ensino e investigação". Nesta missão geral incluem-se as seguintes vertentes principais:

1. Planejar, apoiar e controlar um SGQ inclusivo;

2. Através de procedimentos simples, integrar nas tarefas correntes os mecanismos de avaliação e de melhoria;

3. Promover a "cultura da qualidade".

Ainda, considerando como uma referência na implantação e institucionalização de SGQ, cita-se novamente a Universidade do Porto e, assim, destaca-se que, em março de 2016 foi instituído o Grupo Dinamizador da Qualidade e Melhoria Contínua na U.Porto ${ }^{9}$, que integrou representantes das entidades constitutivas, abarcando docentes, não docentes e estudantes. 0 reforço e a consolidação da qualidade foram assumidos como elementos estratégicos na gestão da U.Porto, como se pode confirmar nos sucessivos planos estratégicos e grandes linhas de ação.

\footnotetext{
${ }^{9}$ https://goo.gl/ejb2IC
}

Periódico Horizontes - USF - Itatiba, SP - Brasil - e020074 
Destaca-se como pilares fundamentais do SIGQ, a promoção do autoconhecimento, a elaboração e disponibilização de relatórios anuais sobre a desempenho da IES, sempre que possível em comparação nacional e, quando for o caso, também em âmbito internacional.

É importante notar que a prática deste exercício ao longo dos anos, permitirá a disponibilização de séries temporais longas que evidenciam a evolução da instituição e de seus cursos em diversos domínios, a saber, caracterização de população estudantil: estudantes inscritos, caracterização socioeconômica, percurso dos estudantes diplomados, empregabilidade, desenvolvimento de projetos e infraestruturas, internacionalização, e demais aspectos que se fizerem necessários.

Um outro pilar que merece destaque na caracterização de um SIGQ consiste nos procedimentos de garantia da qualidade, abrangendo a recolha de informação e a produção de indicadores em diversas áreas, incluindo a apreciação da eficiência e eficácia da sua implementação, num processo cíclico de análise, aplicação e reanálise, que conduz à melhoria contínua do próprio sistema, com o aperfeiçoamento e inclusão de novos módulos, revelando a preocupação da IES em monitorar, avaliar e aperfeiçoar o seu SIGQ.

Em função das experiências institucionais, ao longo do desenvolvimento e utilização do sistema, certamente surgirá a necessidade de se desenvolver novos módulos para aprimoramento dos procedimentos de monitoramento e avaliação, para a geração de novos relatórios de avaliação de desempenho de recursos humanos docentes e não docentes.

Nesta perspectiva, ainda se considera necessário fazer referência ao pilar que diz respeito ao acompanhamento e avaliação do desempenho da IES, tendo como base o monitoramento da performance institucional e demonstrando como se podem utilizar, com êxito, indicadores de desempenho fora do tradicional contexto da qualidade.

Por fim, comenta-se o pilar que consiste no Manual do SIGQ, que deverá ser concebido como um esforço de aperfeiçoamento, ampliação, consolidação e formalização do sistema de gestão da qualidade institucional.

O princípio norteador do SIGQ é a ideia de que uma verdadeira cultura da qualidade só se consegue quando os procedimentos de garantia da qualidade não se distinguem dos procedimentos de gestão, e quando todos os atores se identificam com os seus princípios e contribuem ativamente para o seu uso e melhoria. 
Assim, o Manual do SIGQ estará permanentemente em construção, num processo contínuo de meta avaliação, conducente à introdução de novos procedimentos e práticas, e à correção dos já existentes, constituindo desta forma um documento dinâmico.

\section{Considerações finais}

Na busca por respostas coerentes que contemplassem a complexidade do tema elencado neste estudo, percorreu-se caminhos sinuosos, contraditórios, conflituosos e por vezes subjetivos. Estes propiciaram inquietação, dúvida, reflexão, ponderação, debate, análise e conhecimento.

Tal caminho foi percorrido objetivando analisar os processos regulatórios e avaliativos de IES vigentes em Portugal, por meio dos Sistemas Internos de Garantia da Qualidade (SIGQ) para, assim, estabelecer proposições junto ao modelo Brasileiro, de modo a favorecer os processos de autorregulação.

A experiência vivida em Portugal, teve um caráter inspirador para alguém que levou consigo, no decorrer deste percurso, o objetivo já citado, vivenciando as práticas de avaliação e regulação portuguesas, por meio das quais se constatou o quanto a maturidade de um sistema educacional pode contribuir com os processos.

Motivo pelo qual não se propôs por meio deste estudo a adoção de práticas idênticas as lusitanas, por entender que o sistema educacional brasileiro não possui, até então, o mesmo nível de maturidade. Identificou-se, nesse modelo inspirador, a força que processos de monitoramento e avalições internas possuem dentro da perspectiva de amadurecimento e qualificação dos sistemas educacionais, em especial aqueles que tratam da autorregulação.

E assim, como resposta ao tema apresentado, o estudo revelou que um processo favorecerá a qualidade na medida em que tenha como base de sustentação mecanismos de autorregulação robustos, bem desenvolvidos e de forma contínua, com credibilidade junto à comunidade acadêmica e estruturado por meio de sistemas internos de garantia de qualidade.

As concepções e orientações respeitadas neste processo de elaboração de proposições junto a autorregulação de IES, efetivadas por meio deste estudo, são consonantes e, consubstanciam com o princípio fundamental de que a qualidade, bem como a sua garantia, são 
de responsabilidade, em primeiro lugar, das próprias IES. Dessa forma, foi proposto em primeiro plano a institucionalização de sistemas internos de garantia da qualidade por parte das IES, sendo tais sistemas passíveis de certificação pelos órgãos reguladores.

Deste modo, espera-se contribuir junto ao debate referente aos processos de autorregulação na Educação Superior brasileira, sem, contudo, ter a falsa ilusão de que este estudo por si só produzirá melhores resultados no sistema educacional como um todo.

\section{Referências}

APPOLINÁRIO, F. Dicionário de metodologia científica: um guia para a produção do conhecimento científico. São Paulo: Atlas, 2009.

BANDURA, A. Self-regulation of motivation through anticipatory and selfreactive mechanisms. Nebraska: University of Nebraska Press, 1991.

BANDURA, A. AZZI, G. POLYDORO, S. Teoria social cognitiva - conceitos básicos. Porto Alegre: Artmed, 2008.

BARDIN, L. Análise de conteúdo. Lisboa: LDA, 2009.

CHIZZOTTI, A. Pesquisa qualitativa em ciências humanas e sociais. Petrópolis: Vozes, 2006.

FONSECA, J. J. S. Metodologia da pesquisa científica. Fortaleza: UEC, 2002.

GIL, A. C. Como elaborar projetos de pesquisa. São Paulo: Atlas, 2007.

GONÇALVES, E. P. Iniciação à pesquisa científica. Campinas: Alínea, 2001.

JOSÉ, F. M. Pesquisa: contornos no processo educativo. Franca: FHDSS, 2006.

LÜDKE, M.; ANDRÉ, M. E. D. A. Pesquisa em educação: abordagens qualitativas. São Paulo: EPU, 1986.

MAY, T. Pesquisa social: questões, métodos e processo. Porto Alegre: Artmed, 2004.

MINAYO, M. C. S. Pesquisa social: teoria, método e criatividade. Petrópolis: Vozes, 2001.

OLIVEIRA, M. M. Como fazer pesquisa qualitativa. Petrópolis: Vozes, 2007.

PORTUGAL. A3ES. Pedido de acreditação prévia de novo ciclo de estudos. Lisboa: 2016a.

Disponível em: http://www.a3es.pt/pt/acreditacao-e-auditoria/guioes-e-

Periódico Horizontes - USF - Itatiba, SP - Brasil - e020074 
procedimentos/acreditacao-previa-de-novos-ciclos-de-estudos. Acesso em: 08 fev. 2020.

PORTUGAL. Manual da qualidade. Aveiro: 2016b. Disponível em:

https://www.ua.pt/sigq/page/22105. Acesso em: 10 out. 2020.

PORTUGAL. Manual do sistema de gestão. Coimbra: 2016c. Disponível em:

https://www.uc.pt/damc/manual/manual_sistema_gestao_15. Acesso em: 10 fev. 2020.

PORTUGAL. Manual do sistema de gestão da qualidade da universidade do Porto. Porto: $2016 \mathrm{~d}$.

Disponível em: https://sigarra.up.pt/up/pt/web_page.Inicial. Acesso em: 09 set. 2020.

SÁNCHEZ, G. S. Pesquisa em educação: métodos e epistemologias. Chapecó: Argos, 2012.

SILVA, K. R. X. Desafios ao enriquecimento curricular no curso de Educação Física. Rio de Janeiro: Uniabeu, 2013.

TRIVIÑOS, A. N. S. Introdução à pesquisa em ciências sociais: a pesquisa qualitativa em educação. São Paulo: Atlas, 1987.

Recebido em maio 2020.

Aprovado em dezembro 2020. 